琴 HARVARD Kennedy School

JOHN F. KENNEDY SCHOOL OF GOVERNMENT

\author{
Faculty Research Working Papers Series
}

\title{
On the Philosophy of Group Decision Methods II: \\ Alternatives to Majority Rule
}

\author{
Mathias Risse \\ John F. Kennedy School of Government - Harvard University
}

November 2008

RWP08-065

The views expressed in the HKS Faculty Research Working Paper Series are those of the author(s) and do not necessarily reflect those of the John F. Kennedy School of Government or of Harvard University. Faculty Research Working Papers have not undergone formal review and approval. Such papers are included in this series to elicit feedback and to encourage debate on important public policy challenges. Copyright belongs to the author(s). Papers may be downloaded for personal use only. 


\title{
On the Philosophy of Group Decision Methods II: Alternatives to Majority Rule
}

\author{
Mathias Risse \\ John F. Kennedy School of Government, Harvard University \\ October 30, 2008 \\ (forthcoming in Philosophical Compass)
}

\begin{abstract}
In this companion piece to "On the Philosophy of Group Decision Methods I: the Non-Obviousness of Majority Rule," we take a closer look at some competitors of majority rule. This exploration supplements the conclusions of the other piece, as well as offer a further-reaching introduction to some of the challenges this field currently poses to philosophers.
\end{abstract}

1. Despite its ubiquity, standard arguments in support of majority rule fail to respond to straightforward complaints about its applications. ${ }^{1}$ These arguments mostly ignore the spectrum of alternative decision rules. Throughout most of history minorities rather than majorities have ruled. So having arguments against minority regimes matters, and those standard arguments meet that purpose. Alas, now that we rarely see intellectual defenses of minoritarian regimes, the challenge for advocates of majoritarian decision making is to muster arguments against rules that are neither explicitly anti-majoritarian nor prominoritarian, but whose rationales do not turn on counting heads.

The companion piece explored weaknesses of arguments for majority rule and offered a rationale for majority rule that included a straightforwardly pragmatic component. The present piece seeks to continue this exploration by looking at some competing decision methods. Yet first we must discuss in more detail than the companion piece what should count as majoritarian decision making for more than two options.

\footnotetext{
${ }^{1}$ For this, see the companion piece: "On the Philosophy of Group Decision Methods I: the NonObviousness of Majority Rule." Many thanks to Tony Laden and two anonymous referees for comments on this piece.
} 
("Options" are what individuals rank.) The trouble stems from the Condorcet Paradox, named after an $18^{\text {th }}$ century French nobleman, the Marquis the Condorcet. Suppose three people (A, B, C) seek to rank candidates $(1,2,3)$ by using majority rule. Suppose A ranks them $(1,2,3), \mathrm{B}(2,3,1)$, and $\mathrm{C}(3,1,2)$. By majority rule, 1 is preferred to 2 , and 2 to 3 , but 3 is preferred to 1 . Instead of a ranking they obtain a cycle. It is not that this method delivers a tie among rankings; it delivers no result at all.

Section 2 offers a general account of majoritarian decision making in light of these difficulties and articulates the need for a general philosophical theory of decision rules. The remaining sections explore two debates that must inform this theory. Section 3 and 4 look at the debate between majoritarian decision making and its cousin and competitor, the Borda count. For $\mathrm{n}$ options, Borda has each voter assign n-1 to the firstranked option, $\mathrm{n}-2$ to the second-ranked, etc, while the group decides by summing over these numbers and by ranking the options beginning with the one with the highest number. ${ }^{2}$ It turns out that majoritarian decision making and Borda are reasonable group decision methods under the same conditions. Section 5 looks at fair division methods. Champions of such methods may object that any aggregation of rankings is unfair under certain conditions. ${ }^{3}$ The conclusion looks back at these discussions in terms of the

\footnotetext{
${ }^{2}$ Notice the following two equivalent descriptions of Borda: To begin with, suppose all votes between any two options are taken. Then for each option, the number of elections is counted in which any agent prefers this option to the respective alternative. If A obtains a Borda count of 23, then in 23 cases some voter, confronted with a pair including A, prefers A. Yet another characterization of the Borda count is that it ranks the options starting with the one with the highest average position across all rankings.

${ }^{3}$ I draw on Risse (2004) and Risse (2005). One problem beyond the scope of this paper that has recently attracted attention is the so-called $n$ Discursive Dilemma (more generally, the topic if judgment aggregation). This dilemma shows that majority voting on logically connected issues can generate an inconsistent set of judgments or goals. Suppose a group of three, X, Y and Z, vote on whether A, whether B and whether $\mathrm{A} \& \mathrm{~B}$. $\mathrm{X}$ and $\mathrm{Y}$ vote for $\mathrm{A}, \mathrm{Y}$ and $\mathrm{Z}$ for $\mathrm{B}$, so that only $\mathrm{Y}$ will support $\mathrm{A} \& \mathrm{~B}$. So majority rule commits the group to A, B and (not-A\&B). See List (2006) for an introduction; see also Bovens and Rabinowicz (2006).
} 
aforementioned general philosophical theory of group decision methods: these discussions provide fragments of this theory and are explored here in hopes of creating more interest in this sort of work.

2. If majority rule for more than two options means taking consecutive pairwise votes, the Condorcet Paradox shows that majority rule will not always deliver a decision. Kenneth Arrow's Impossibility Theorem, in one way of thinking about it, generalizes the phenomenon displayed in the Paradox. ${ }^{4}$ In light of these results, some (e.g., Wolff (1970), Hardin (1993)) argue that majoritarian democracy is conceptually flawed, insisting that there is no coherent, general majoritarian way of making decisions.

Yet there is a way of generalizing majority rule to $\mathrm{m}$ options in a coherent manner. I have called that generalization the Condorcet proposal because of affinities to ideas of the Marquis de Condorcet. ${ }^{5}$ Instead of taking all pairwise votes and hoping they can be assembled into a ranking, this proposal looks at all votes on the $m(m-1) / 2$ pairs among the $\mathrm{m}$ options and selects one or more of the $\mathrm{m}$ ! rankings of $\mathrm{m}$ options in light of these votes, regardless of cycles. The idea is to select a ranking with maximal support through these votes. Suppose a group of 48 must rank A, B, and C. 10 people rank them $(\mathrm{A}, \mathrm{B}, \mathrm{C}), 12(\mathrm{~A}, \mathrm{C}, \mathrm{B}), 5(\mathrm{~B}, \mathrm{~A}, \mathrm{C}), 7(\mathrm{~B}, \mathrm{C}, \mathrm{A}), 3(\mathrm{C}, \mathrm{B}, \mathrm{A})$ and $11(\mathrm{C}, \mathrm{A}, \mathrm{B})$. So we have $3 !=6$ rankings and $3(3-1) / 2=3$ pairwise votes. The ranking with highest support is (A, C, B): In A vs. B, 33 people support it (33 people rank A over B), in B vs. C 26

\footnotetext{
${ }^{4}$ See Arrow (1963), and for discussion of the issues raised by Arrow's theorem, see Sen (1986) and Pildes and Anderson (1990). Seen Austen-Smith and Banks (2000) and (2005) for a broadly-based recent discussion of social choice theory.

${ }^{5}$ For this proposal and a fuller defense, see Risse (2001). Of course, this method violates one of Arrow's (1963) axioms, but that is of no avail to the claim that it captures what we should mean by majoritarian decision making.
} 
people, and in A vs. C 27. So 86 votes support (A, C, B), compared to 82 for (A, B, C),

64 for $(\mathrm{B}, \mathrm{A}, \mathrm{C}), 58$ for $(\mathrm{B}, \mathrm{C}, \mathrm{A}), 62$ for $(\mathrm{C}, \mathrm{B}, \mathrm{A})$, and 80 for $(\mathrm{C}, \mathrm{A}, \mathrm{B})$. This procedure is never indeterminate, though it might deliver ties. As far as tied rankings are concerned, there is nothing more to say from a majoritarian standpoint. ${ }^{6}$

Two lines of defense support the claim that this proposal is a generalization of majoritarian voting. On the one hand, the proposal possesses features that make it reasonable to consider it a majoritarian proposal. On the other hand, the proposal is supported by suitable generalizations of all arguments in support of majority rule presented above, except May's theorem. ${ }^{7}$ Let me just illustrate the second claim for one of the standard arguments offered in support of majoritarian decision making, which was introduced in the companion piece:

\footnotetext{
${ }^{6}$ The Condorcet proposal is equivalent to two other well-known decision rules. To begin with, the same rankings as those selected by the proposal emerge when we apply a generalized Condorcet Jury Theorem, as shown by Young (1988) and (1997). The Condorcet Jury Theorem says the following: Suppose $n$ agents choose between two options; that each has a probability of $p>1 / 2$ of being right; and that their probabilities are independent of each other (i.e., they make up their minds for themselves). Then, as $\mathrm{n}$ grows, the probability of a majority's being right approaches 1 . Young (1988) demonstrates that Condorcet (1785) himself provides an idea for a generalization of the theorem. Young describes Condorcet's theorem in terms of maximum likelihood estimation. To illustrate this for two options: Suppose each person has a probability of $p>1 / 2$ of being right. Of 20 voters, 12 favor A over B, and 8 rank B over A. Suppose A over $B$ is the correct ranking. Then this result occurs with probability $(20 ! / 12 ! 8 !) p^{12}(1-p)^{8}$. Suppose that B over $\mathrm{A}$ is correct. Then the result has probability $(20 ! / 12 ! 8 !) p^{8}(1-p)^{12}$, which is smaller than $(20 ! / 12 ! 8 !) p^{12}(1-p)^{8}$ for $p>1 / 2$. So the assumption that $A$ over $B$ is correct bestows maximal likelihood on the result. We infer that ranking A over B, rather than B over A, is correct. This point of view extends to $m$ options. The procedure is to go through all $\mathrm{m}$ ! rankings and calculate the conditional probability of the pairwise voting results given that the respective ranking is the correct one. The ranking that bestows maximum likelihood to the voting result is chosen. There is a third approach identifying those same rankings. That approach (Kemeny's rule, see Kemeny (1959)) searches for a compromise among rankings. Forming their "average" suggests itself. This operation presupposes a notion of distance between rankings. Define this distance as the number of pairs with regard to whose ranking two rankings differ. The distance between $(\mathrm{A}, \mathrm{B}, \mathrm{C})$ and $(B, A, C)$ is 1: they differ only with regard to $\{A, B\}$. A suitable conceptualization for an average of rankings is their median relative to this metric, the ranking minimizing the sum over the distances from the rankings. This median is also the result of the maximum likelihood method and the recommendation of the proposal. Strikingly, three very different methods select the same rankings.

${ }^{7}$ It is for these reasons - on which I cannot expand here - that I favor the Condorcet proposal as the sensible account of majoritarian decision making over a number of other rules that coincide with pairwise majority rule in the absence of cycles. For details, see Risse (2001); for alternative rules, see Riker (1982), chapter 4.
} 
Maximization: Majority rule maximizes the number of people who exercise selfdetermination. This argument evidently generalizes to whichever property one thinks is expressed in the act of voting or realized by winning an election.

Strictly speaking, Maximization does not generalize. Self-determination is realized in votes, but rankings are not subject to voting, according to the Condorcet proposal. Yet the proposal maximizes the number of voting acts expressing self-determination. For two options, this argument is the original Maximization. The generalization should be convincing to whomever Maximization was convincing.

Given that majoritarian decision making is well-defined for the general case, when is it appropriate? As the companion piece shows, standard arguments for majority rule fail to address a proposal that, say, a committee should make a hiring decision by using a 100-point system. Would that system be as reasonable as the Condorcet proposal or Borda? Or can we distinguish conditions under which ordinal rankings are appropriate (rankings in which we only know which options are preferred to which others) from conditions under which other rankings are (e.g., rankings that include information about relative strengths of preferences)? What can we say about the relative merits of Borda and Condorcet when only rankings of options matter?

Such questions call for a theory of group decision methods that assesses, first, the conditions under which particular kinds of rankings are appropriate (e.g., ordinal or point systems), including an account of when rankings should not be decisive for the group choice at all (if, say, fair division methods are more appropriate); second, what specific voting method(s) is (are) appropriate for the specific kinds of rankings, as well what methods are appropriate instead when rankings ought not to be decisive; and third, what the criteria for appropriateness are in these cases. This is a field full of philosophical 
challenges. While recent decades have seen much work on formal properties of decision rules, the philosophy of group decision making has been neglected. We do not have a theory of group decision methods of this sort.

3. Let us explore some questions that arise in the development of this theory. Suppose we have already ascertained under what conditions aggregating rankings is the appropriate way of making a decision. Is then the Condorcet proposal or the Borda count more reasonable? While there are arguments showing both methods to be reasonable, no argument conclusively establishes one as more reasonable than the other. Under the proposal, some people will be "losers" although they would not be had Borda been adopted, an equally reasonable rule, and vice versa. While majoritarian decision making is conceptually sound, it never is the uniquely reasonable method. A vigorous case for Borda has recently been made by Donald Saari. Saari thinks the Borda count can be derived from basic and compelling ideas. ${ }^{8}$

For the thesis that Condorcet cannot defeat Borda and vice versa, I offer two sorts of arguments, or parts thereof. First, arguments for the proposal each have a counterpart that supports Borda, and vice versa. Second, we will look at Saari's case for Borda and show that advocates of Condorcet need not accept it. Let me illustrate the first strategy by looking at two arguments for the proposal. One is Maximization, the other a generalization of the Condorcet Jury Theorem:

Condorcet's Jury Theorem: Supposes it makes sense to speak of being right or wrong about political decisions. Suppose $\mathrm{n}$ agents choose between two options;

\footnotetext{
${ }^{8}$ For Saari's case, see (2000a-c), Saari and Merlin (2000), Saari (2003), and Saari and Sieberg (2001); Dummett (1984) and (1998) is another defender of the Borda Count. Saari (2003) is a response to Risse (2001). Risse (2005) takes up the discussion again, and Saari (2006) responds.
} 
that each has a probability of $\mathrm{p}>1 / 2$ of being right; and that their probabilities are independent of each other (i.e., they make up their minds for themselves ${ }^{9}$ ). Then, as $\mathrm{n}$ grows, the probability of a majority's being right approaches 1 .

In other words, and roughly speaking: If individual group members make up their minds independently and tend to be right more commonly than wrong, the probability of the majority being right becomes ever greater as the group size increases. According to the generalized Condorcet Jury Theorem, rankings selected by the proposal bestow the highest likelihood on the election results among pairwise votes. So the assumption that a ranking chosen by the proposal is the correct one bestows a higher probability on the occurrence of the actual election results among pairs than any other ranking. Conversely, an inference to the best explanation leads to the conclusion that the observed election results have been generated by one of the rankings chosen by the proposal. ${ }^{10}$

However, the option ranked highest by Borda is the single option that, if best, bestows highest probability upon the voting results, at least if the voters' probability of being right is close to $1 / 2$ (cf. Young (1988), (1997)). So if asked to make an inference to the best explanation in such a way that a single option rather than a ranking is targeted, we are led to the Borda winner. Condorcet selects rankings with the highest support; Borda ranks options in terms of their support. Borda ranks alternatives in terms of their rightness, Condorcet seeks to find the right ranking. Similarly, in the epistemic scenario (where we assume decisions to be "true" or "false"), Condorcet selects rankings of maximal likelihood, and Borda ranks options by their likelihood. Or consider

\footnotetext{
${ }^{9}$ For discussion and extensions of Condorcet's theorem, cf. Grofman et al. (1983), Estlund and Waldron (1989). For discussion of the epistemic conception of democracy, which most prominently needs that assumption, cf. Cohen (1986), Copp (1993), Estlund (1993).

${ }^{10}$ See footnote 6 above for more on this subject.
} 
Maximization. Borda maximizes agreement among rankings, not acts of selfdetermination. Having its own maximandum, Borda fails to be convinced by Maximization. As far as rules for aggregating rankings are concerned, neither Condorcet nor Borda has conclusive arguments against the other.

In his positive case for Borda, Saari formulates two seemingly innocuous "neutrality criteria." Accepting both commits us to Borda. Both define sets of rankings whose removal should not affect the outcome since those sets create a tie. The first is the Neutral Reversal Requirement (NRR). Call two rankings "opposing” if they rank any two alternatives in reverse order. (Example: $(\mathrm{A}, \mathrm{B}, \mathrm{C}),(\mathrm{C}, \mathrm{B}, \mathrm{A})$ ) ) NRR stipulates that voting results remain unchanged when such rankings are removed. If two people disagree about each issue, the group choice should not change if they leave. The second condition is the Neutral Condorcet Requirement (NCR). To explain, I introduce Condorcet n-tuples. "To define this configuration with the four candidates A, B, C, and D," Saari explains, "start with any ranking of them, say, (A, B, C, D). Next, move the top-ranked candidate to the bottom to obtain $(\mathrm{B}, \mathrm{C}, \mathrm{D}, \mathrm{A})$. Continue this process to create the four rankings $(\mathrm{A}, \mathrm{B}, \mathrm{C}$, D), (B, C, D, A), (C, D, A, B), and (D, A, B, C), where, by construction, each candidate is ranked in each position precisely once. With three candidates, the initial ranking $(\mathrm{C}, \mathrm{B}$, A) generates the Condorcet triplet (C, B, A), (B, A, C), and (A, C, B)" (Saari (2003), p 343).

NCR stipulates that group choices remain invariant with regard to the removal of Condorcet n-tuples. The rationale for NCR is that "[s]ince the construction ranks each candidate in each position precisely once, no candidate has an advantage over any other candidate" (Saari (2003), p 343). This argument draws on fairness to candidates. Yet it is 
puzzling how such fairness bears on assessing which voters can be removed without affecting "the will of the people." Since the Condorcet proposal satisfies NRR, NRR creates no contrast between Condorcet and Borda. NCR, however, does. Suppose the Condorcet triplet $(\mathrm{C}, \mathrm{B}, \mathrm{A}),(\mathrm{A}, \mathrm{C}, \mathrm{B})$, and $(\mathrm{B}, \mathrm{A}, \mathrm{C})$ is removed. Looking at the situation from the standpoint of disagreements about pairs, we notice that the view "A is preferred to $\mathrm{B}$ " loses one vote; "B is preferred to A" loses two; "A is preferred to C" loses one, "C is preferred to $\mathrm{A}$ " loses one, "B is preferred to $\mathrm{C}$ " loses one, and "C is preferred to $\mathrm{B}$ " loses two. Three positions lose two votes, and three lose one. For each pair, one view (say, "C is preferred to B") loses two votes, whereas its opposite ("B is preferred to C") loses one. NCR is not neutral with regard to disagreements about pairs.

4. So as far as information about relative standing in rankings is concerned, NCR captures an aspect of neutrality, but not as far as impact on pairwise disagreements is concerned. Reflection on pairs generates a different criterion, the Neutral Balance Requirement. Suppose we have a set of rankings $M=\left\{R_{1}, \ldots, R_{1}\right\}$, for a natural number 1 . Consider the set $\mathrm{PM}=\left\{(\mathrm{A}, \mathrm{B})_{\mathrm{i}}\right.$ : $\mathrm{A}$ and $\mathrm{B}$ are alternatives, and there exists a ranking $\mathrm{R}_{\mathrm{i}}$, $1 \leq i \leq 1$, in $M$ such that $A$ is ranked ahead of $B$ in $R_{i}$. If, say, $M$ consists of $R_{1}=(A, B$, C) and $\mathrm{R}_{2}=(\mathrm{C}, \mathrm{A}, \mathrm{B})$, then $\mathrm{PM}=\left\{(\mathrm{A}, \mathrm{B})_{1},(\mathrm{~A}, \mathrm{C})_{1},(\mathrm{~B}, \mathrm{C})_{1},(\mathrm{C}, \mathrm{A})_{2},(\mathrm{C}, \mathrm{B})_{2},(\mathrm{~A}, \mathrm{~B})_{2}\right\}$. The indexing ensures that, in this case, the pair (A, B) is counted twice, since A is ranked ahead of B both in $(\mathrm{A}, \mathrm{B}, \mathrm{C})$ and in $(\mathrm{C}, \mathrm{A}, \mathrm{B})$, and in general to make sure that each pair is counted as many time as it appears in that order in some ranking in $\mathrm{M}$. Call a set $\mathrm{M}=$ $\left\{\mathrm{R}_{1}, \ldots, \mathrm{R}_{1}\right\}$ balanced if there exist sets $\mathrm{PM}_{1}, \ldots, \mathrm{PM}_{\mathrm{m}}$, for a natural number $\mathrm{m}$, such that (a) $\mathrm{PM}$ is the union over all $\mathrm{PM}_{\mathrm{i}}, 1 \leq \mathrm{i} \leq \mathrm{m}$; (b) the intersection of any $\mathrm{PM}_{\mathrm{i}}$ and $\mathrm{PM}_{\mathrm{j}}, 1 \leq \mathrm{i} \neq$ 
$\mathrm{j} \leq \mathrm{m}$ is empty; and (c) for all such $\mathrm{i}, \mathrm{PM}_{\mathrm{i}}=\left\{(\mathrm{A}, \mathrm{B})_{\mathrm{j}},(\mathrm{B}, \mathrm{A})_{\mathrm{k}}\right.$, for some alternatives $\mathrm{A}$ and $\mathrm{B}$ and some rankings $\mathrm{R}_{\mathrm{i}}$ and $\mathrm{R}_{\mathrm{k}}$ in $\left.\mathrm{M}\right\} .{ }^{11}$

$\mathrm{M}$ is balanced, that is, if for any pair (A, B) anywhere in rankings in $\mathrm{M}$, the opposing pair (B, A) also occurs in some ranking, and the set PM of all pairs that occur anywhere in some ranking in $\mathrm{M}$ (which by construction lists all pairs as many times as they occur in rankings in $\mathrm{M}$ ) is a disjoint union over pairs (A, B) and their opposing pairs (B, A). For an example, consider $\mathrm{M}=\{(\mathrm{A}, \mathrm{B}, \mathrm{C}, \mathrm{D}),(\mathrm{C}, \mathrm{B}, \mathrm{A}, \mathrm{D}),(\mathrm{A}, \mathrm{D}, \mathrm{C}, \mathrm{B}),(\mathrm{D}, \mathrm{B}, \mathrm{C}$, A), (B, D, A, C), (C, D, A, B)\}. To see that this is a balanced set, note that (A, B, C, D) contributes the ordered pairs (A, B), (A, C), (A, D), (B, C), (B, D), and (C, D) to PM, (C, B, A, D) the pairs (C, B), (C, A), (C, D), (B, C), (B, D), and (C, D)), and so on. (B, D), for instance, occurs twice already, and the indexing makes sure (B, D) occurs in PM as many times as it occurs in any ranking in M. Once the reader has constructed PM in this manner, it will be easy to see that PM is a disjoint union over sets including only a pair and its opposite (such as (A, B) and (B, A)). As opposed to that, the set $\{(\mathrm{A}, \mathrm{B}, \mathrm{C}, \mathrm{D}),(\mathrm{A}$, $\mathrm{D}, \mathrm{C}, \mathrm{B}),(\mathrm{B}, \mathrm{C}, \mathrm{A}, \mathrm{D})$ \} is not balanced: the ranking $(\mathrm{A}, \mathrm{B}, \mathrm{C}, \mathrm{D})$ ranks $\mathrm{A}$ ahead of $\mathrm{D}$, but there is no ranking in this set that ranks $\mathrm{D}$ ahead of $\mathrm{A}$.) The set $\mathrm{M}=\{(\mathrm{A}, \mathrm{B}, \mathrm{C}, \mathrm{D}),(\mathrm{C}, \mathrm{B}$, $\mathrm{D}, \mathrm{A}),(\mathrm{B}, \mathrm{D}, \mathrm{C}, \mathrm{A}),(\mathrm{D}, \mathrm{B}, \mathrm{C}, \mathrm{A})\}$ is not balanced either: though it is true that for each pair that is ranked somewhere the opposing pair also appears in $\mathrm{M}$, the pair $(\mathrm{C}, \mathrm{A})$ occurs three times in PM, but (A, C) occurs only once. Opposing rankings form balanced sets, but there are balanced sets free from opposing rankings (if there are more than three alternatives - set M just discussed is an example).

\footnotetext{
${ }^{11}$ To keep the notation simple, "A" and "B" sometimes denote fixed alternatives and sometimes function as variables ranging over alternatives; it should be clear, in each case, what is meant.
} 
The Neutral Balance Requirement (NBR) stipulates that the decision remain unchanged if balanced sets are removed. The rationale for NBR is that removing such sets does not affect the strength of views on the relative standing of pairs vis-à-vis opposing pairs. Both Condorcet and Borda satisfy NBR. So Condorcet satisfies NRR and NBR, but not NCR, whereas Borda satisfies NRR, NBR, and NCR. The crucial question becomes: why impose NCR in addition to NRR and NBR and thus impose a criterion that, as Saari shows, leads straight to Borda? We cannot answer this question without endorsing commitments vis-à-vis the purposes of the aggregation, such as "criterion $\mathrm{X}$ should be adopted because the purpose of aggregating rankings is such and such." Suppose somebody finds NRR and NBR persuasive because the removals licensed by these criteria leave invariant the relative standing of pairs vis-à-vis their opposites. Asked to elaborate, this person would say she thinks the purpose of the aggregation is to assess how strongly rankings are supported by pairwise votes, and if rankings are removed in such a manner that for each pair (A, B) that loses the support of one voter, so does its opposing pair $(\mathrm{B}, \mathrm{A})$, then the support for each possible ranking that could be the group choice will decrease by the same amount. Somebody with such a view would reject NCR because NCR does not remove pairs under such conditions. Reasoning about these criteria as suggested in this paragraph, one commits oneself to views about aggregation embodied by the Condorcet proposal.

To support the view that NCR should be adopted in addition to NRR and NBR, Saari may say NCR is persuasive because no information about relative standing of candidates vanishes if we remove a Condorcet n-tuple. Saari may add that arguments of this sort also support NRR and NBR: both criteria leave the relative standing of 
candidates unchanged. Yet to rebut the view sketched in the preceding paragraph, Saari must say that the purpose of aggregating rankings is to assess such relative standing and then rank candidates accordingly. That is what Borda does: ask about the support for each option in all rankings. But Condorcet does something else, and we can account coherently and reasonably for what it is. Both rules capture robust views on aggregation.

5. The Borda count cannot defeat the Condorcet proposal as a decision rule under conditions where groups ought to make choices by aggregating ordinal rankings, and vice versa. As far as defenses of majoritarian decision making are concerned, this is mixed news. Majoritarian decision making is reasonable when we can be sure that aggregating rankings is the appropriate way of making decisions. But the proposal never is the uniquely most reasonable method. Let us reinforce the negative side of this news by taking a look at the theory of fair division. This discussion further qualifies support for majoritarian decision making: We have learned so far that such decision making is never uniquely reasonable, and a closer look at the theory of fair division now will question the appropriateness of deciding by using rankings in the first place, including the appropriateness of deciding in a majoritarian manner.

Fair division theories consider the following type of situation: ${ }^{12}$ There are goods to which several parties make claims, or "bads" with regard to which they have obligations. These goods or bads may be divisible (land, costs, a cake) or indivisible (houses, children for custody, seats in congress); they may be concrete (land) or abstract (honors, positions, or, on the negative side, household chores, taxation). Although the

\footnotetext{
${ }^{12}$ Characteristic works in the area of fair division include (with varying degrees of philosophical and formal emphasis) Elster (1992), Young (1994), and Brams and Taylor (1996).
} 
field is called "fair division," it is best understood as dealing with the arbitration of competing claims, which may not always literally "divide" anything. A dispute about a corner office may be resolved by a seniority principle, which would neither entail that the office be divided, nor that all claims succeed to some extent.

Although fair division tends to be discussed context-specifically, there are only a few principles that cut across disparate domains. To begin with, there is envy-freeness: nobody should be left with a preference for somebody else's share. Proportionality requires that each of the $\mathrm{n}$ agents perceive the value of his own share as counting for at least $1 / \mathrm{n}$ of what is distributed, while equitability demands that each agent receive a share that is at least as good in her view as what anybody else receives in his view. Impartiality ensures agents sharing all relevant characteristics obtain the same portion. Consistency guarantees that any two individuals would divide what is allotted to them in a way that agrees with what they obtain in the overall process. These principles conflict, especially for more than two agents and if efficiency matters.

We are looking at the theory of fair division to explore how majoritarian decision making may conflict with fairness. To have a convenient way to make the point, let me resort to some notions used not as principles of division, but as devices to re-describe situations calling for fair division in such a way that the principles apply. Consider a custody dispute. A common solution is a rotation scheme: the child spends some time with each parent. Divided is the child's time, and how it is divided can be determined by some of those principles. Or suppose one city must provide a site for a waste dump. This city could be compensated by other cities so that all carry an equal burden. By permitting compensation we make the principles applicable. Compensation and rotation fail to apply 
when the question is who should receive transplants, or which survivor should be sacrificed for the others. Priority criteria could be set up (preferably in an impartial and consistent way), and among those with equal priority, a lottery might determine the ranking. Randomization allows the application of fairness principles to the distribution of access to indivisible goods. Randomization, like rotation and compensation, associates an indivisible good with a closely related divisible good to which principles of fair division apply. Another such device is forced equality. Sometimes a good cannot be made available to everybody with a claim. One solution is not to give it to anybody: it would be okay for some people to walk across the lawn, but not everybody should, and if no good criterion for selecting "the few" is available, we may prohibit it generally. ${ }^{13}$

In the companion piece we considered a scenario where "we" and "they" are two adversarial schools of thought in a philosophy department. They have the majority. The department has to decide whether to hire a philosopher from their camp or from ours. It is easy to apply the concepts just introduced to formulate objections to majority rule based on fairness. If the job is a renewable one-year job, one may suggest a rotation scheme to which proportionality criteria apply (or other principles mentioned above): If "they" are $60 \%$ and "we" $40 \%$, they may fill the job for three years, we for two. Or we may suggest a compensation scheme to which once more proportionality applies: maybe "we" get a part-time hire next year, or a conference. Or we may suggest "forced equality:" maybe it is better to hire nobody. The theory of fairness, as opposed to majority rule, provides resources to reach group decisions under circumstances of radical and persistent disagreement that allow for claims to be accommodated proportionately.

\footnotetext{
${ }^{13}$ For these topics, see Young (1994), chapter 1.
} 
One may be reluctant to thinking about hiring in terms of fair division, especially in terms of principles such as envy-freeness and equitability. Such principles, one may say, are suitable for dividing inheritances, not for appointments. This objection succeeds if the faculty judge the candidates by the same criteria. However, if their only common ground is that the different schools of thought recognize each other as factions that for the sake of peace cannot be ignored, then hiring is like dividing an inheritance. Circumstances of radical and persistent disagreement are characterized by the absence of shared criteria for decision-making, except that all sides are interested in a continued collective existence. As opposed to majority rule, fair division, one may say, can allow for dignified and respectful decision making.

Let me offer a proposal of a lottery-based fair-division scheme for a scenario when several candidates need to be ranked. ${ }^{14}$ Suppose a group of $\mathrm{n}$ must rank $\mathrm{m}$ candidates $\left(\mathrm{C}_{1}, \ldots ., \mathrm{C}_{\mathrm{m}}\right)$. So we have $\mathrm{n}$ rankings of the $\mathrm{m}$ candidates. In the first step, we count how many times each candidate is listed first in the $\mathrm{n}$ rankings. This delivers numbers $C_{1}(1), \ldots ., C_{m}(1)$ such that $0 \leq C_{i}(1) \leq n($ for $1 \leq i \leq m)$ and $\Sigma_{1 \leq j \leq n} C_{j}(1)=n$. The numbers $C_{1}(1) / n, \ldots ., C_{m}(1) / n$ give us the percentages with which the $m$ candidates are listed in the first rank. We take these percentages as the probabilities of a random device that determines the top candidate of the group. That candidate, $\mathrm{C}_{\mathrm{i}}$, is removed from the $\mathrm{n}$ rankings. We then look at $n$ rankings of $(m-1)$ candidates and determine numbers $C_{1}(2) / n$, $\ldots, \mathrm{C}_{\mathrm{i}-1}(2) / \mathrm{n}, \mathrm{C}_{\mathrm{i}+1}(2) / \mathrm{n}, \ldots ., \mathrm{C}_{\mathrm{m}}(2) / \mathrm{n}$, which provide percentages with which the remaining

\footnotetext{
${ }^{14}$ The job can go only to one person, but it might be good to have back-ups. I made this proposal in Risse (2004). As far as I know, it has not been further explored yet.
} 
candidates are listed in what is now the top row. Next we use our device to determine the second-ranked candidate, etc.

The procedure has the following features: If one candidate is the top-ranked candidate for each individual, she becomes the top-ranked candidate of the group. Generally, if candidate $C_{j}(1 \leq j \leq m)$ is ranked by each individual at the $i$-th place $(1 \leq i \leq m)$, the group ranking will list $\mathrm{C}_{\mathrm{i}}$ at the $\mathrm{j}$-th place or above. If everybody prefers one candidate to another, the group ranking preserves this agreement. Most importantly, this procedure preserves, step by step, the proportionate strength of the views on the candidates. If the group agrees that all candidates still under consideration are appointable, they have decided by unanimity to the point up to which this was feasible, and from then on decide in a way that preserves all relevant views in proportion. Majoritarian voting may disagree with the result of this procedure. But that merely highlights that majority rule fails to consider all relevant views in proportion. That is, it show that majoritarian voting is -- unfair.

6. Let us take stock. We saw above that we need a theory of group decision methods that assesses, first, the conditions under which particular kinds of rankings are appropriate (e.g., ordinal or point systems), including an account of when rankings should not be decisive for group choice at all (if, e.g., fair division methods are appropriate instead); second, what specific voting method(s) is (are) appropriate for the specific kinds of rankings, as well what methods are appropriate instead when rankings ought not to be decisive; and third, what the criteria for appropriateness are in these cases. Our discussion of Condorcet vs. Borda and our discussion of fair division methods as competitors to 
decision making by aggregation provide fragments of that theory, fragments we have explored at the exclusion of other topics that would fit here as well.

More specifically, we have seen the following: First, in those cases where we can assume that decision making should proceed by aggregating rankings in which only

ordinal information is used, both the Borda count and the Condorcet proposal are reasonable rules. Majoritarian decision making, though reasonable under the relevant circumstances, never is uniquely reasonable. Second, there is a range of decision scenarios where fair division methods rather than aggregation of preferences are appropriate. We have not attempted clearly to delineate the circumstances under which the one rather than the other is appropriate. Instead, our purpose has been simply to make clear that, across a range of cases, fair division methods indeed are competitors to majoritarian decision making, or for that matter to any decision making by aggregation. More work is needed to understand under what conditions what kind of decision rule ought to apply. Much more work, generally, is needed towards the sort of theory of group decision methods I have sketched. My goal has been to create more interest in this work.

\section{Literature}

Arrow, Kenneth. 1963. Social Choice and Individual Value. $2^{\text {nd }}$ edition. New Haven: Yale University Press

Austen-Smith, David, and Jeffrey Banks. 1998. Positive Political Theory I: Collective Preference. Ann Arbor: University of Michigan Press

Austen Smith, David, and Jeffrey Banks. 2005. Positive Political Theory II: Strategy and Structure. Ann Arbor: University of Michigan Press 
Bovens, Luc, and Wlodek Rabinowicz. 2006. "Democratic Answers to Complex Questions: An Epistemic Perspective.” Synthese 150 (1): pp 131-153

Brams, Steven. and Alan Taylor. 1996. Fair Division. Cambridge: Cambridge University Press

Cohen, Joshua.1986. “An Epistemic Conception of Democracy.” Ethics 97: 26-38

Condorcet, Marquis de. 1785. Essai sur l Application de l Analyse à la Probabilité des Décisions Rendues à la Probabilité des Voix, Paris: De 1 Imprimière Royale

Copp, David. 1993. “Could Political Truth be a Hazard for Democracy?” In Copp at al (1993)

Copp, David, Jean Hampton, and John Roemer (eds.). 1993. The Idea of Democracy. Cambridge: Cambridge University Press

Dummett, Michael. 1984. Voting Procedures. Clarendon Press, Oxford

Dummett, Michael. 1998. "The Borda Count and Agenda Manipulation." Social Choice and Welfare 15: 289-296

Elster, Jon. 1992. Local Justice. New York: Russell Sage Foundation Estlund, David. 1993. "Making Truth Save for Democracy.” In Copp et al. (1993) Estlund, David. and Jeremy Waldron. 1989. "Democratic Theory and the Public Interest: Rousseau and Condorcet Revisited." American Political Science Review 83, $1317-1340$

Grofman, Bernard, Guillermo Owen, and Scott Feld. 1983. "Thirteen Theorems in Search of the Truth.” Theory and Decision 15: 261-278

Hardin, Russell. 1993. "Public Choice Versus Democracy.” In Copp et al. (1993) 
Kemeny, John. 1959. “Mathematics Without Numbers.” Daedalus 88: 571-591

List, Christian. 2006. "The Discursive Dilemma and Public Reason." Ethics 116(2): pp 362-402

Mueller, Dennis (ed). 1997. Perspectives on Public Choice. Cambridge: Cambridge University Press

Pildes, Richard, and Elisabeth Anderson. 1990. "Throwing Arrows at Democracy: Social Choice Theory, Value Pluralism, and Democratic Politics," Columbia Law Review $8,2121-2216$

Riker, William. 1982. Liberalism Against Populism. San Francisco: Freeman

Risse, Mathias. 2001. “Arrow's Theorem, Indeterminacy, and Multiplicity Reconsidered”. Ethics, Vol. 111, pp 706-734

Risse, Mathias. 2004. “Arguing for Majority Rule.” Journal of Political Philosophy, Vol. 12, No. 1, pp 41-64

Risse, Mathias. 2005. "Why the Count de Borda Cannot Beat the Marquis de Condorcet," Social Choice and Welfare 25 (1): pp 95-113

Saari, Donald. 2000a. "Mathematical Structure of Voting Paradoxes I: Pairwise Votes." Economic Theory 15: 1-53

Saari, Donald. 2000b. "Mathematical Structure of Voting Paradoxes II: Positional Voting." Economic Theory 15: 55-101

Saari, Donald. 2000c. Decisions and Elections. Explaining the Unexpected. Cambridge University Press, Cambridge

Saari, Donald. 2003. "Capturing the 'Will of the People'." Ethics 113: 333-34 
Saari, Donald. 2006. "Which Better: the Condorcet or Borda Winner?" Social Choice and Welfare 26 (1): pp 107-129

Saari, Donald, and Vincent Merlin. 2000. "A Geometric Examination of Kemeny's Rule." Social Choice and Welfare 17: 403-438.

Saari, Donald and Katri Sieberg (2001) "The Sum of the Parts Can Violate the Whole.”American Political Science Review 95: 415-30

Sen, Amartya. 1986."Social Choice Theory," Kenneth Arrow and Michael Intrilligator (eds.), Handbook of Mathematical Economics III, 1073-1183, Amsterdam: North-Holland

Wolff, Robert Paul. 1970. In Defense of Anarchism. Harper and Row, New York City

Young, Peyton (1997). “Group Choice and Individual Judgments.” In: Mueller (1997)

Young, Peyton. 1994. Equity in Theory and Practice. Princeton: Princeton University Press 